\title{
PAPER
}

\section{Incidence and case fatality rates of stroke subtypes in a multiethnic population: the South London Stroke Register}

\author{
C D A Wolfe, A G Rudd, R Howard, C Coshall, J Stewart, E Lawrence, C Hajat, T Hillen
}

J Neurol Neurosurg Psychiatry 2002;72:21 1-216

See end of article for authors' affiliations

Correspondence to: Dr C Wolfe, Department of Public Health Sciences, Capital House, 42 Weston Street, London SE 1 3QD, UK; charles.wolfe@kcl.ac.uk

Received 8 June 2001 In revised form 21 August 2001

Accepted 24 August 2001

\begin{abstract}
Objective: To identify sociodemographic differences in the incidence of the subtypes of first ever stroke in a multiethnic population.

Methods: A prospective community stroke register (1995-8) was developed using multiple notification sources and pathological and clinical classifications of stroke. Standardisation of rates was to European and World populations and adjusted for age, sex and socioeconomic status in multivariate analyses. A multiethnic population of 234533 in south London, of whom $21 \%$ are black was studied. Results: A total of 1254 cases were registered. The average age of stroke was 71.7 years with black patients being 11.3 years younger than white patients $(p<0.0001)$. The incidence rate/1000 population was 1.33 (crude) $(95 \% \mathrm{Cl} 1.26$ to 1.41$), 1.28$ (European adjusted) $(95 \% \mathrm{Cl} 1.2$ to 1.35$)$ with a $2.18(95 \% \mathrm{Cl} 1.86$ to 2.56$)(\mathrm{p}<0.0001)$ age and sex adjusted incidence rate ratio in the black population. Radiological diagnosis was confirmatory in 1107 (88.3\%) with 862 (68.7\%) infarction, 168 $(13.4 \%)$ primary intracerebral haemorrhage, and $77(6.2 \%)$ subarachnoid haemorrhage. Of the cerebral infarction cases 189 (21.9\%) were total anterior circulatory, 250 (29\%) partial anterior, 141 (16.4\%) posterior (POCl) and $282(32.7 \%)$ lacunar infarcts. The black group had a significantly higher incidence of all subtypes of stroke except for $\mathrm{POCl}$ and unclassified strokes. The incidence rate ratio (IRR) for men compared with women was 1.34 (95\% confidence interval $(95 \% \mathrm{CI}) 1.19$ to 1.50 ; $\mathrm{p}<0.001)$. The IRR for manual versus non-manual occupations in those aged 35-64 years was 1.64 $(95 \% \mathrm{Cl} 1.22$ to $2.23 ; \mathrm{p}<0.0001)$. There was a borderline significant increase in adjusted survival at 6 months in the black group $95 \%(\mathrm{Cl} 0.61$ to $1.03, p=0.078)$ with a hazard ratio of 0.79 after adjustment and stratification.

Conclusions: Although the black population is at increased risk of stroke and most subtypes of stroke, this is not translated into significant differences in survival. Hence black/white differences in mortality are mainly driven by incidence of stroke. There are striking demographic inequalities in the risk of stroke in this multiethnic inner city population that need to be tackled through interagency working. Although the reasons for the increased risk in the black population are unclear, demographic factors such as socioeconomic status do seem to play a significant independent part.
\end{abstract}

I n many countries Governments have set targets to reduce stroke mortality without understanding the major influences on these rates, be they risk of the disease or survival after the stroke. ${ }^{1}$ Developing strategies to reduce the impact of stroke in society are hampered without accurate incidence data and an understanding of the effect of sociodemographic as well as clinical factors on risk.

Black people have higher stroke mortality rates than white people in the United Kingdom and the United States. ${ }^{2-4}$ In Britain, black Caribbean people have the highest stroke mortality rates but the differences with other ethnic groups have reduced substantially in recent years. ${ }^{2}$ Howard et al estimated in the United States that in men $14 \%$ to $46 \%$ of the excess risk of death from stroke can be explained by socioeconomic status although this did not hold true for women. ${ }^{5}$

Stroke incidence rates in different white populations worldwide have been determined and vary considerably. ${ }^{67}$ Studies in the United States have shown a twofold to threefold increase in incidence in the black population and have suggested that this may account for the excess mortality rates in this group, although none of the studies established whether black-white differences in incidence were confounded by socioeconomic status..$^{8-10}$

Hart et $a l^{1112}$ investigated stroke incidence differentials by socioeconomic position in adulthood and showed that in a young white population risk factors for stroke can explain some of the socioeconomic differences in stroke risk. It seems that adverse early life circumstances were of particular importance. ${ }^{12}$

Kunst et al have found increased mortality rate ratios in manual classes across Europe ${ }^{13}$ but these studies do not allow the influence of incidence, case severity, and case fatality to be assessed.

In the various incidence studies, the incidence of all subtypes of stroke is reported to be increased in the black population but particularly intracerebral haemorrhage and subarachnoid haemorrhage. 8 -10 1415

There is inconsistent evidence on whether there are differences in survival between black and white people in the United States ${ }^{4}{ }^{14}$ although it would seem overall that survival is poorer in the black population.

The South London Stroke Register (SLSR) was established to investigate ethnic differences in the natural history of stroke. ${ }^{16}{ }^{17}$ Initial findings reported that the overall incidence rate ratio for stroke was 2.2 in the black population compared with the white population. This paper considers for the first time the incidence of first in a lifetime stroke by clinical subtype

Abbreviations: $\mathrm{POCl}$, posterior cerebral infarction; IRR, incidence rate ratio; SLSR, South London Stroke Register; ONS, Office of National Statistics; $\mathrm{TACl}$, total anterior cerebral infarction; $\mathrm{PACl}$, partial anterial cerebral infarction; LACI, lacunar infarction; OCSP, Oxford Community Stroke Project 
and adjusts for the specific effect of certain socioeconomic and demographic factors on both the risk of the subtypes of stroke and survival at 6 months in a multiethnic community.

\section{METHODS}

A population based stroke register recording first in a lifetime strokes only, using the World Health Organisation clinical definition, in patients of all age groups was set up using standard criteria and has been described in detail elsewhere. ${ }^{17}$ A summary is outlined here. Data were collected prospectively by the registry team comprising a medical researcher and nurse trained research associates. Using 12 referral sources in hospital, the local community and neighbouring hospitals, stroke cases were identified as resident in a defined area corresponding to 22 wards of Lambeth, Southwark, and Lewisham Health Commission. Ethical consent was obtained from the Guy's and St Thomas's research ethics committee in accordance with the Helsinki Declaration of 1975, revised in 1983. The total population (234 533) is $72 \%$ white, $21 \%$ black (11\% black Caribbean, $7.5 \%$ West African, and $2.5 \%$ black mixed), and 3\% Asian, Bangladeshi, and Pakistani with 4\% "other". Hospital surveillance of stroke admissions included two teaching hospitals within and three outside the study area. Community surveillance of stroke included patients under the care of all general practitioners within and on the borders of the study area $(n=147)$. The notification sources were accident and emergency departmental records, hospital wards, brain imaging requests, death certificates, coroners' records, general practitioners, hospital medical staff, community therapists, bereavement officers, hospital based stroke registries, general practice, computer records, and "miscellaneous", including notification by patients or relatives of patients.

Methods used to ensure complete case ascertainment included personal visits to all general practitioners before the project started and 1 year later, regular communication by telephone, and posters and quarterly newsletters. Use of a weekly stroke clinic or domiciliary visit by the study team was also available to general practitioners.

Death certificates with an International Classification of Diseases 9th series, codes 430 to 434 and 436 were validated according to clinical registration criteria. The Office of National Statistics (ONS) notified the SLSR of any patients who had died, whatever they had died of.

Initial assessments were performed by a research team medical practitioner. Registration criteria and data collected were checked with the patient's general practitioner and medical records. Patients with transient neurological deficits were included but if the deficit resolved within 24 hours they were not registered. Patients were examined within 48 hours of referral to SLSR where possible. Information collected at initial assessment included self defined ethnicity (1991 census question), and socioeconomic status (Registrar General's codes based on occupation ${ }^{17}$ ). In the United Kingdom a standard method of inferring socioeconomic status from occupation is used ${ }^{15}$ which is a proxy for education and income. Patients were asked their regular occupation or, if they were retired, their last full time occupation. Women were assigned their own occupation, with the exception of housewives, who were assigned their husband's or father's occupation. Ethnic origin was stratified into three groups: "black" (black Caribbean, black African,and black other), "white", and other (Asian, Pakistani, Indian, Bangladeshi, Chinese, and other). Socioeconomic status categories were grouped in a standard fashion into non-manual (I, II, and III non-manual), manual (III manual, IV, and V) and economically inactive (student, unemployed, unable to work due to disability, carer, and if retired with no data from which to categorise the patient from last employment $\left.{ }^{11}{ }^{12}{ }^{18}\right)$. These data were collected whenever possible on all patients but this proved problematic in the elderly population who were often unable to communicate or remember their last occupation or that of their spouse. This study therefore reports socioeconomic status only in those patients aged 35-64. This is the only age group in which routine statistics were reliable on the background denominator population for socioeconomic status.

Classification of pathological stroke type (cerebral infarction, primary intracerebral haemorrhage, and subarachnoid haemorrhage) was based on results from at least one of the following: brain imaging performed within 30 days of stroke onset (CT or MRI), CSF analysis (in all living cases of subarachnoid haemorrhage where brain imaging was not diagnostic) or necropsy examination. Cases without pathological confirmation of stroke subtype were unclassified. The clinical classification of stroke was that described by Bamford et al for cerebral infarction and includes total anterior cerebral infarction (TACI), partial anterial cerebral infarction (PACI), posterior cerebral infarction (POCI), and lacunar infarction (LACI). ${ }^{19}$

The denominators for the incidence rate calculations were the 1996 adjusted estimates of the 1991 Office of National Statistics' census data for the study area using 10 year age groups $(0-14 ; 15-24$ to $75-84 ;>84)$. Sex and ethnic group specific incidence rates were age adjusted to standard European and World populations for comparative purposes. To enable comparisons with the MONICA populations age adjusted rates were also calculated for ages 35-64 only. ${ }^{6}$ Confidence intervals for the age specific rates and age adjusted rates were calculated using the Poisson distribution. Incidence rate ratios for black to white were calculated using Poisson regression, adjusting for age and sex. Incidence rate ratios were also calculated to examine ethnic differences in incidence for each subtype of stroke adjusting for age and sex. As socioeconomic status data are ill defined in those aged under 35 or over 64 in this population, a further Poisson regression, adjusted for age, sex, and socioeconomic status was performed on cases aged 35-64.

Survival time was measured from date of stroke to date of death. Those still alive were censored at the last known date alive as confirmed by ONS (29/11/00).

Unadjusted survival after stroke was estimated by the Kaplan-Meier method and comparisons between black and white ethnic groups were made using the log rank test. Cox's stratified proportional hazards model was used to compare survival between ethnic groups adjusted for sex and stratified by age group, socioeconomic status, and stroke subtype. Model assumptions were examined using Schoenfeld residuals.

\section{RESULTS}

The SLSR registered 1254 patients with first in a lifetime stroke over 4 years. Of the 1254 patients registered, 607 (48.4\%) were males and 647 (51.6\%) females; 995 (79.4\%) were white, $203(16.2 \%)$ were black and $52(4.2 \%)$ were of other ethnic origins with four $(0.3 \%)$ of unknown ethnic origin. There were only three patients with mixed black ethnicity. The mean age of all first strokes was 71.7 years (range 0 to 106(SD 14.3)). The mean age was 73.9 years for white patients (range 0 to 106 (SD 13)), 62.6 years for black patients (range 17 to 94 (SD 15.5)), and 66 years for others (range 29 to 89 (SD 13) $(p<0.0001)$. Overall, there were $292(23.3 \%)$ non-manual, $705(56 \%)$ manual, and $243(19.4 \%)$ other employment categories with $14(1.1 \%)$ with no employment status ascertained. Overall 943 (75.2\%) were retired, 156 (12.4\%) employed, and 118 (9.4\%) unemployed before the stroke.

Radiological (CT/MRI) diagnosis of stroke subtype was confirmed in 1107 (88.3\%) cases. The distribution of subtypes was cerebral infarction $862(68.7 \%)$, primary intracerebral haemorrhage 168 (13.4\%), subarachnoid haemorrhage 77 $(6.2 \%)$, and $147(11.7 \%)$ were unclassified. Of these unclassified cases, $38(25.9 \%)$ were community patients and 32 


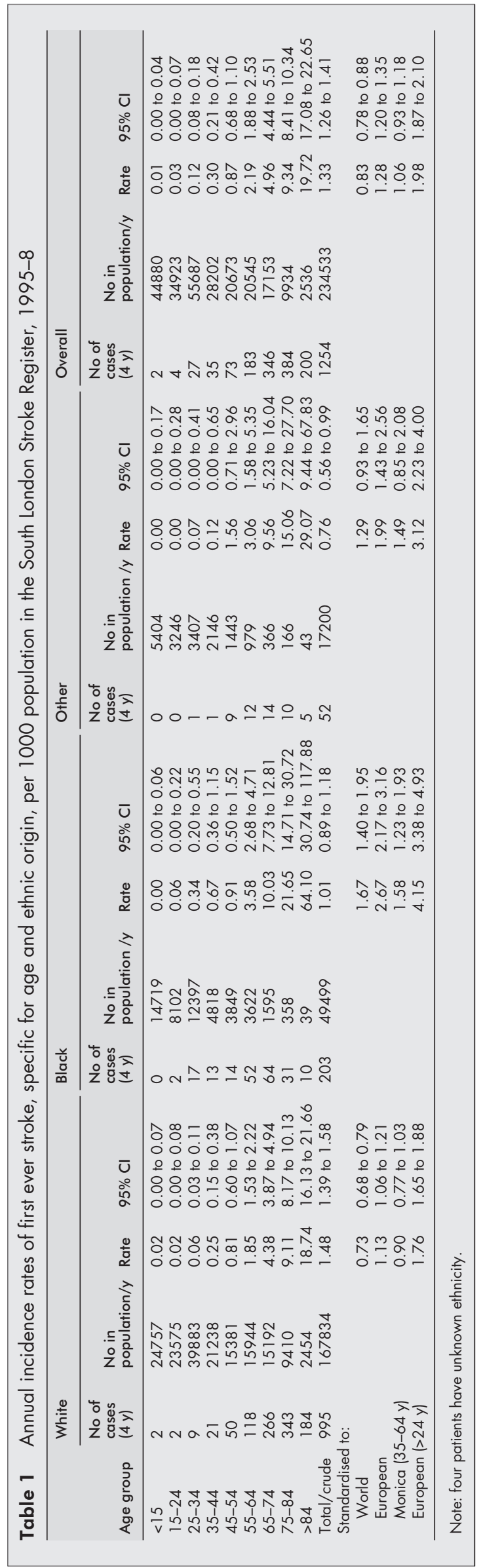

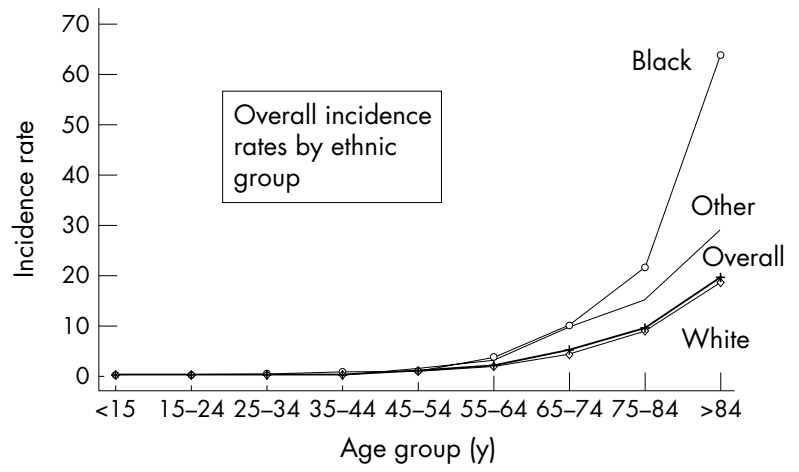

Figure 1 Overall incidence rates by ethnic group.

(21.8\%) patients (five community, 27 hospital) died within 48 hours of stroke onset. Of the $77 \%$ of patients with scan times, $75 \%$ had their scan within 7 days and $80 \%$ within 10 days.

The Oxford Community Stroke Project (OCSP) classification of the cerebral infarction cases was $189(21.9 \%)$ TACI, 250 (29\%) PACI, 141 (16.4\%) POCI, and 282 (32.7\%) LACI.

The crude total incidence rate/1000 population was 1.33 (95\% CI 1.26 to 1.41 ), 1.28 (95\% CI 1.2 to 1.35 ) standardised to the European, and 0.83 (95\% CI 0.78 to 0.88 ) standardised to the World populations (table 1 ).

Incidence rates (age adjusted to the standard European population) were higher in males than females. The total crude rate in men was 1.35 (95\% CI 1.39 to 1.64 ) and in women 1.33 (95\% CI 0.98 to 1.15). The age adjusted incidence rate ratio for men compared with women was 1.34 (95\% CI 1.19 to $1.50, \mathrm{p}<0.001)$.

In the incidence rate ratio model of the entire sample, two interactions were found: between sex and age group $(p=0.0017)$ as expected; and between sex and ethnicity $(p=0.0355)$ The age adjusted incident rate ratio for black:white people was 1.87 (95\% CI 1.51 to $2.33, \mathrm{p}<0.001$ ) in men and 2.65 (95\% CI 2.09 to $3.34, \mathrm{p}<0.001)$ in women.

Although these interactions existed, the pattern of incidence remained the same and inclusion of the interaction terms did not substantially alter the conclusions drawn. For this reason and due to the smaller numbers in subgroups, the interactive terms were not assessed in other incident rate ratio models.

Across all age groups, incidence rates were higher in black compared with white populations (table 1). The overall black to white age and sex adjusted incidence rate ratio (excluding interactions) was 2.18 (95\% CI 1.86 to $2.56, \mathrm{p}<0.0001)$. Stroke incidence rates increased with age in all ethnic groups and age was a significant independent factor influencing stroke incidence $(\mathrm{p}<0.000 \mathrm{l}$, fig $\mathrm{l})$. The age adjusted incidence rates by pathological and Bamford classification are presented in table 2 by ethnic group. Table 3 outlines the incidence rate ratios, adjusted for age and sex. For all subtypes there was a significantly increased rate ratio in the black group except for POCI and unclassified.

The effect of socioeconomic status on incidence could only be assessed in the 35-64 year age group. The incidence rate ratios for the 35-64 year old patients adjusted additionally for age, sex, ethnicity, and socioeconomic status allows a further insight into the influences on risk in this age group. Again there were increased rate ratios in the black group, although they tended to be less pronounced once controlled for socioeconomic status. The overall black:white incidence rate ratio adjusted for age, sex, and socioeconomic status was 1.69 (95\% CI 1.29 to $2.2, \mathrm{p}<0.001$ ) and without socioeconomic status adjustment was 1.81 ( $95 \%$ CI 1.39 to $2.36, \mathrm{p}<0.0001$ ).

Socioeconomic status for those aged between 35 and 64 was a significant independent factor influencing stroke incidence. The incidence rate ratio between manual (179 cases) and 
Table 2 Annual incidence rates $(95 \% \mathrm{Cl})$ for stroke by subtype and ethnic group, adjusted for age to standard European population/1000 (1995-8)

\begin{tabular}{llll}
\hline Type of stroke & White & Black & Overall \\
\hline$n$ & 151 & 31 & 182 \\
TACl & $0.17(0.14$ to 0.20$)$ & $0.45(0.26$ to 0.65$)$ & $0.18(0.16$ to 0.21$)$ \\
$n$ & 204 & 36 & 240 \\
PACl & $0.23(0.19$ to 0.26$)$ & $0.54(0.29$ to 0.79$)$ & $0.24(0.21$ to 0.27$)$ \\
$n$ & 117 & 17 & 134 \\
POCl & $0.14(0.11$ to 0.16$)$ & $0.18(0.09$ to 0.27$)$ & $0.14(0.11$ to 0.16$)$ \\
$n$ & 224 & 48 & 272 \\
LACl & $0.26(0.22$ to 0.30$)$ & $0.69(0.43$ to 0.96$)$ & $0.28(0.24$ to 0.31$)$ \\
$n$ & 696 & 132 & 828 \\
Cerebral infarction & $0.79(0.73$ to 0.86$)$ & $1.87(1.45$ to 2.29$)$ & $0.84(0.78$ to 0.89$)$ \\
$n$ & 114 & 37 & 151 \\
Primary intracerebral haemorrhage & $0.13(0.11$ to 0.16$)$ & $0.40(0.23$ to 0.58$)$ & $0.16(0.13$ to 0.19$)$ \\
$n$ & 52 & 22 & 74 \\
Subarachnoid haemorrhage & $0.08(0.05$ to 0.10$)$ & $0.18(0.04$ to 0.31$)$ & $0.08(0.06$ to 0.10$)$ \\
$n$ & 132 & 12 & 144 \\
Unclassified & $0.13(0.11$ to 0.16$)$ & $0.20(0.06$ to 0.37$)$ & $0.14(0.11$ to 0.16$)$ \\
\hline Note: four patients have unknown ethnicity. & & \\
\hline
\end{tabular}

\begin{tabular}{|c|c|c|c|}
\hline Stroke subtype & IRR & $95 \% \mathrm{Cl}$ & $\mathrm{p}$ Value \\
\hline $\mathrm{TACl}$ & 2.36 & 1.57 to 3.54 & 0.0001 \\
\hline $\mathrm{PACl}$ & 2.04 & 1.41 to 2.95 & 0.0004 \\
\hline $\mathrm{POCl}$ & 1.40 & 0.83 to 2.36 & 0.2301 \\
\hline $\mathrm{LACl}$ & 2.32 & 1.67 to 3.23 & $<0.0001$ \\
\hline Infarct & 2.10 & 1.73 to 2.56 & $<0.0001$ \\
\hline $\mathrm{PICH}$ & 2.79 & 1.87 to 4.15 & $<0.0001$ \\
\hline SAH & 2.36 & 1.40 to 3.99 & 0.0024 \\
\hline Unclassified & 1.67 & 0.90 to 3.08 & 0.1241 \\
\hline Overall subtypes & 2.18 & 1.86 to 2.56 & $<0.0001$ \\
\hline
\end{tabular}

non-manual groups (63 cases) was 1.65 (95\% CI 1.21 to 2.23 , $\mathrm{p}<0.0001)$. The remaining 40 cases $(14 \%)$ were classified as economically inactive. The overall rates by subtype per 1000 population are given in table 4 . The rates were also significantly higher for cerebral infarction and PICH in manual workers. With regard to the Bamford classification, LACI was significantly more common in manual workers (table 4).

The overall case fatality rates were $16.6 \%(208)$ at 7 days, $25.7 \%(322)$ at 28 days, $32.9 \%(412)$ at 90 days, and $36.7 \%$ (460) at 180 days but with no significant differences between ethnic groups.

Of the 1198 black and white patients, 682 (56.9\%) deaths occurred. For those who died the mean survival/patient was 9.25 months (SD 14.18 months, range 0 to 62.17 months) and a median survival of 1.3 months. The difference between unadjusted survivor functions by ethnic group (fig 2) was significant $(\mathrm{p}<0.0001)$. This was reduced to borderline significance $(95 \%$ CI 0.61 to $1.03, p=0.078$ ) with a hazard ratio of 0.79 after adjustment for sex and stratification for age, socioeconomic class, and stroke subtype.

\section{DISCUSSION}

It is established that there are differences in mortality rates between regions for stroke both in the United Kingdom and
United States but studies to date have failed to link incidence and survival data or to adequately adjust for the type of stroke or sociodemographic differences between the populations. Such detailed analyses could begin to identify the causes of the mortality differences and inform prevention policy. This paper has estimated the incidence of stroke subtypes in a multiethnic population, described this impact by various demographic groups, and assessed the impact of these factors on survival. Obviously it is also necessary to consider other clinical factors such as risk factors and case severity of stroke but this is not within the focus of this detailed analysis of demographic influences on risk and outcome.

\section{Stroke Register methodology}

The validity of any incidence study depends on complete and accurate case ascertainment and we have previously reported our methodology to ensure as complete ascertainment as possible. ${ }^{77}$ We have also estimated the possible underestimate of the SLSR using capture-recapture methodologies to be in the region of $12 \%{ }^{20}$

\section{Stroke incidence}

Total stroke incidence rate of $1.24 / 1000$ population, age adjusted to the standard European population, is within the range of rates reported in registers in Europe and New Zealand. ${ }^{67-23}$ In a comparison between three European populations, in 1995-97, the London incidence rate was in the middle. ${ }^{24}$

The adjusted ratio of black to white stroke incidence rates was 2.2 with an age adjusted black incidence rate at 2.6/1000. This compares with some of the highest reported rates worldwide (2.8/1000 in Japan and 2.9/1000 men in Finland). ${ }^{6}$ The excess black stroke incidence in the SLSR is similar to the 2.4fold increase reported in the ARIC study ${ }^{8}$ and the 2.4 increased risk in the Northern Manhattan Stroke Study. ${ }^{10}$ The estimates presented here are similar to those reported using the first 2 years of data but with narrower confidence intervals. The importance of reporting the 4 year rates in that analysis by clinical stroke subtype has been shown.

\section{Stroke subtype}

The SLSR shows increased incidence rates in black subjects over white subjects for all pathological subtypes, with primary 
Table 4 Annual incidence rates $(95 \% \mathrm{Cl})$ for stroke by subtype and social class, adjusted for age, sex, and ethnic group (35-64 years) to standard European population/1000 (1995-8)

\begin{tabular}{|c|c|c|c|c|}
\hline Type of stroke & Non-manual & Manual & Economically inactive & Overall \\
\hline $\begin{array}{l}\mathrm{n} \\
\mathrm{TACl}\end{array}$ & $\begin{array}{l}12 \\
0.17(0.07 \text { to } 0.28)\end{array}$ & $\begin{array}{l}26 \\
0.25(0.15 \text { to } 0.34)\end{array}$ & $\begin{array}{l}6 \\
0.05 \\
(0.01 \text { to } 0.09)\end{array}$ & $\begin{array}{l}44 \\
0.16(0.11 \text { to } 0.20)\end{array}$ \\
\hline $\begin{array}{l}\mathrm{n} \\
\mathrm{PACl}\end{array}$ & $\begin{array}{l}11 \\
0.18(0.07 \text { to } 0.28)\end{array}$ & $\begin{array}{l}28 \\
0.27(0.17 \text { to } 0.38)\end{array}$ & $\begin{array}{l}4 \\
0.03(0.001 \text { to } 0.06)\end{array}$ & $\begin{array}{l}43 \\
0.16(0.11 \text { to } 0.20)\end{array}$ \\
\hline $\begin{array}{l}\mathrm{n} \\
\mathrm{POCl}\end{array}$ & $9.12(0.04$ to 0.20$)$ & $\begin{array}{l}24 \\
0.23(0.14 \text { to } 0.32)\end{array}$ & $\begin{array}{l}5 \\
0.06(0.004 \text { to } 0.11)\end{array}$ & $\begin{array}{l}38 \\
0.14(0.09 \text { to } 0.18)\end{array}$ \\
\hline $\begin{array}{l}\mathrm{n} \\
\mathrm{LACl}\end{array}$ & $\begin{array}{l}7 \\
0.11(0.03 \text { to } 0.19)\end{array}$ & $\begin{array}{l}48 \\
0.47(0.34 \text { to } 0.60)\end{array}$ & $\begin{array}{l}6 \\
0.05(0.01 \text { to } 0.10)\end{array}$ & $\begin{array}{l}61 \\
0.23(0.17 \text { to } 0.28)\end{array}$ \\
\hline Cerebral infarction & $\begin{array}{l}39 \\
0.58(0.39 \text { to } 0.76)\end{array}$ & $\begin{array}{l}126 \\
1.22(1.01 \text { to } 1.44)\end{array}$ & $\begin{array}{l}21 \\
0.19(0.10 \text { to } 0.27)\end{array}$ & $\begin{array}{l}186 \\
0.68(0.58 \text { to } 0.77)\end{array}$ \\
\hline $\begin{array}{l}\mathrm{n} \\
\text { Primary intracerebral haemorrhage }\end{array}$ & $\begin{array}{l}10 \\
0.13(0.05 \text { to } 0.21)\end{array}$ & $\begin{array}{l}34 \\
0.33(0.22 \text { to } 0.44)\end{array}$ & $\begin{array}{l}7 \\
0.10(0.02 \text { to } 0.18)\end{array}$ & $\begin{array}{l}53 \\
0.19(0.14 \text { to } 0.25)\end{array}$ \\
\hline $\begin{array}{l}\mathrm{n} \\
\text { Subarachnoid haemorrhage }\end{array}$ & $\begin{array}{l}12 \\
0.14(0.06 \text { to } 0.23)\end{array}$ & $0.12(0.05$ to 0.19$)$ & $\begin{array}{l}5 \\
0.08(0.01 \text { to } 0.14)\end{array}$ & $\begin{array}{l}30 \\
0.11(0.07 \text { to } 0.15)\end{array}$ \\
\hline $\begin{array}{l}\mathrm{n} \\
\text { Unclassified }\end{array}$ & $\begin{array}{l}2 \\
0.03(0 \text { to } 0.07)\end{array}$ & $\begin{array}{l}7 \\
0.07(0.02 \text { to } 0.12)\end{array}$ & $\begin{array}{l}7 \\
0.06(0.02 \text { to } 0.11)\end{array}$ & $\begin{array}{l}17 \\
0.06(0.03 \text { to } 0.09)\end{array}$ \\
\hline$\stackrel{n}{\text { Overall }}$ & $\begin{array}{l}63 \\
0.88(0.65 \text { to } 1.10)\end{array}$ & $\begin{array}{l}179 \\
1.74(1.48 \text { to } 1.99)\end{array}$ & $\begin{array}{l}40 \\
0.42(0.28 \text { to } 0.57)\end{array}$ & $\begin{array}{l}286 \\
1.04(0.92 \text { to } 1.17)\end{array}$ \\
\hline
\end{tabular}

Note: four patients missing due to unknown social class in the range 35-64 y.

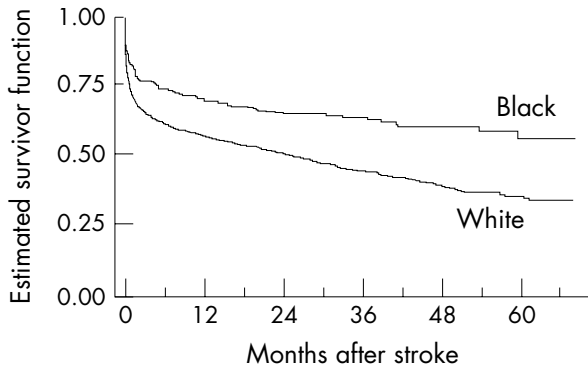

Figure 2 Estimated Kaplan-Meier survivor function by ethnic group.

intracerebral haemorrhage having the highest black: white incidence rate ratio. Higher rates of haemorrhagic stroke have been reported in black subjects and of embolic strokes and extracranial occlusive vascular disease in white subjects..$^{8-10} 1415$ There was also an increased risk in the black population across all OCSP subtypes, although not reaching significance in the POCI and unclassified groups. Further work on estimating the risk factors in the different ethnic groups by subtype has been undertaken to try and explain these differences. ${ }^{25}$ This study based on the SLSR data showed that physiological risk factors for stroke were similar in black and white groups, but behavioural risk factors differ. The OCSP subtypes bear little association with risk factors. Compared with the OCSP data the London Study had an increased proportion of TACI $(22 \% v 17 \%)$ and LACI $(32.7 \% v$ $25 \%$ ) with lower proportions of POCI and PACI which may be due to ethnic variation or other risk factor differences.

\section{Socioeconomic status}

The measurement of the socioeconomic status is complex and the measures used will not capture all aspects of status. Variables such as employment status, educational level, income, and deprivation scores have all been used. ${ }^{11}$ The weakness of previous studies is that they report the association of socioeconomic status with younger strokes (usually under 65 years). Although we were able to describe the incidence rates for all ages using only one measure, we were unable to study the influence of socioeconomic status on incidence due to lack of reliable data for the general local population.

Ethnic differences in socioeconomic status have been suggested as being contributory to the excess black stroke mortality over that of white subjects in the United States. Adjustment for socioeconomic status has not been performed in any published stroke incidence study including black subjects or in subtypes of stroke. We have been able to report the incidence rates by clinical and pathological subtype for the first time. In SLSR socioeconomic status adjustment of incidence rates was only possible within the limited age range (35-64) in which census data on social class were available for the background population. There are problems with the Registrar General's coding of socioeconomic status particularly in the exclusion of housewives, carers, students, and the unemployed, but it was the only measure available in this study. Although the reduced sample size of stroke cases aged 35-64 meant that the confidence intervals of black:white incidence rate ratios after adjustment for socioeconomic status were wide, ethnicity was still significantly associated with stroke incidence. Increased stroke incidence in lower socioeconomic groups in both black and white populations in SLSR is consistent with socioeconomic group variation in stroke mortality and incidence reported in other studies. ${ }^{1122627}$ The reported rate ratio between manual and non-manual groups was 1.65 , which is similar to that reported by Hart et al. ${ }^{11}$ We used a self definition of ethnic group, which is a standard approach. ${ }^{17}$ There are suggestions of other variables that can be collected by researchers to describe ethnicity such as genetic markers, observer assigned ethnicity, country of birth, religion, and years of residence in country. ${ }^{28}$

\section{Risk factors}

The excess stroke incidence in the black over the white population was not explained by social class, age, or sex. Differences in genetic, physiological, and behavioural risk factors accounting for ethnic differences in stroke incidence do require further elucidation. A higher prevalence of hypertension and diabetes among black subjects compared with white subjects 
has been reported ${ }^{29}$ and a recent study suggests ethnic differences in genetic predisposition to hypertension. ${ }^{30}$

Hart et al have shown that the adjusted hazard ratios for incidence with socioeconomic class 1 as baseline was 1.62 (95\% CI 0.9 to 2.89 ) when adjusted for age and 1.24 (95\% CI 0.69 to 2.24 ) when controlled for stroke risk factors. ${ }^{11}$

\section{Survival}

Case fatality at 28 days was $26 \%$, which is comparable with rates reported of $18 \%$ and $33 \%$ in two Italian centres. ${ }^{6}$ Compared with 28 day case fatality rates reported in MONICA (ages $35-64$ ), of $15 \%$ to $49 \%$ in men and $18 \%$ to $57 \%$ in women, the SLSR rate of $17 \%$ (for the same age group) is towards the lower end of the ranges and comparable with rates reported in Nordic populations. ${ }^{6}$ Some studies have suggested ethnic differences in survival from stroke. ${ }^{4811}$ In SLSR, there was a borderline statistically significant black:white difference in survival after stroke although there was a non-significant poorer outcome in the white population. Further investigation of the risk factors for stroke, stroke severity, and poststroke management is required to ascertain why these differences exist. Previous survival rates in black populations have had conflicting results but overall it would seem that survival is poorer in the black population studies in the United States. ${ }^{48} 14$

\section{CONCLUSION}

This study has shown important sociodemographic differences in stroke incidence by stroke subtype. Investigation of ethnic differences in risk factors for stroke is needed to account for the excess black stroke incidence to effectively plan stroke prevention and management in multiethnic communities. Similarly, further investigation of stroke severity is required to explain the differences in case fatality and survival.

\section{ACKNOWLEDGEMENTS}

We thank all the patients and their families and the health care professionals involved. Funding was by the Northern and Yorkshire NHS Research and Development programme in Cardiovascular Disease and Stroke, the Charitable Foundation of Guy's and St Thomas' Hospitals, and the Stanley Thomas Johnson Foundation, Switzerland.

\section{Authors' affiliations}

C D A Wolfe, C Coshall, J Stewart, E Lawrence, C Hajat, T Hillen, Department of Public Health Sciences, GKT School of Medicine, Capital House, 42 Weston Street, London SE I 3QD, UK

A G Rudd, Department Care of Elderly, Guy's and St Thomas' Hospital Trust, London, UK

R Howard, Department of Neurology, Guy's and St Thomas' Hospital

Trust, London, UK

\section{REFERENCES}

1 Secretary of State for Health. Our healthier nation: a strategy for health in England. London: The Stationery Office, 1998

2 Balarajan R. Ethnicity and variations in the nation's health. Health Trends 1995:27:114-19.

3 Howard G, Anderson R, Sorlie P, et al. Ethnic differences in stroke mortality between non-Hispanic whites, Hispanic whites, and blacks. The National Longitudinal Mortality Study. Stroke 1994;25:2120-5.
4 Gillum RF. Stroke mortality in blacks. Disturbing trends. Stroke 1999;30:1711-15.

5 Howard G, Russell GB, Anderson R, et al. Role of social class in excess Black stroke mortality. Stroke 1995;26:1759-63.

6 Thorvaldsen P, Asplund K, Kuulasmaa K, et al. Stroke incidence, case fatality and mortality in the WHO MONICA project. Stroke 1995;26:361-7.

7 Sudlow CLM, Warlow CP. Comparable studies of the incidence of stroke and its pathological types. Results from an international collaboration. Stroke 1997;28:491-9

8 Rosamund WD, Folsom AR, Chambless LE, et al. Stroke Incidence and survival among middle-aged adults. 9-year follow-up of the atherosclerosis risk in communities (ARIC) cohort. Stroke 1999;30:736-43

9 Broderick J, Brott T, Kothari R, et al. The greater Cincinnati/northern Kentucky stroke study: preliminary first-ever and total incidence rates of stroke among blacks. Stroke 1998;29:415-21.

10 Sacco R, Boden-Albala B, Gan R, et al. Stroke incidence among white black, and Hispanic residents of an urban community. Am J Epidemiol 1998; 147:259-68.

11 Hart CL, Hole DJ, Smith GD. The contribution of risk factors to stroke differentials, by socioeconomic position in adulthood: the Renfrew/Paisley study. Am J Public Health 2000;90:1788-91.

12 Hart CL, Hole DJ, Smith GD. Influence of socioeconomic circumstances in early and later life on stroke risk among men in a Scottish cohort study. Stroke 2000;31:2093-7.

13 Kunst A, del Rios M, Groenhof F, et al. Socioeconomic inequalities in stroke mortality among middle-aged men: an international overview. Stroke 1998;29:2285-91

14 Lackland DT, Bachman DL, Carter TD, et al. The Geographic variation in stroke incidence in two areas of the southeastern stroke belt. The Anderson and Pee Dee stroke study. Stroke 1998;29:2061-8.

15 Qureshi AI, Giles WH, Croft JB. Racial differences in the incidence of intracerebral haemorrhage. Effects of blood pressure and education. Neurology 1999;52:1617-21

16 Wolfe C, Taub N, Woodrow J, et al. Does the incidence, severity, or case fatality of stroke vary in southern England? J Epidemiol Community Health 1993:47:139-43.

17 Stewart JA, Dundas R, Howard RS, et al. Ethnic differences in incidence of stroke: prospective study with stroke register. BM 1999;318:967-71.

18 Office of Population Censuses and Surveys. Standard occupational classification. London, HMSO 1991

19 Bamford J, Sandercock P, Dennis M, et al. Classification and natural history of clinically identifiable subtypes of cerebral infarction. Lancet 1991;337:1521-6.

20 Tilling K, Sterne JAC, Wolfe CDA. Estimation of the incidence of stroke using a capture-recapture model including covariates. Int J Epidemiology (in press).

21 Bonita R, Beaglehole R, North JDK. Event, incidence and case-fatality rates of cerebrovascular disease in Auckland, New Zealand. Am J Epidemiol 1984;120:236-43.

22 Lemesle M, Milan C, Faivre J, et al. Incidence trends of ischemic stroke and transient ischemic attacks in a well-defined French population from 1985 through 1994. Stroke 1999;30:371-7.

23 Kolominsky-Rabas PL, Sarti C, Heuschmann PU, et al. A prospective community-bsed study in stroke in Germany: the Erlangen stroke project (ESPro): incidence and case fatality at 1, 3 and 12 months. Stroke 1998:29.2501-6.

24 Wolfe CDA, Giroud M, Kolominsky-Rabas P, et al. Variations in Stroke incidence and survival in 3 areas of Europe. Stroke 2000;31:2074-9.

25 Hajat C, Dundas R, Stewart JS, et al. Cerebrovascular risk factors and stroke subtypes. Differences between ethnic groups. Stroke 2001;32:37-42.

26 Casper M, Wing S, Strogatz D. Variation in the magnitude of black-white differences in stroke mortality by community occupational structure. J Epidemiol Community Health 1991;45:302-6.

27 Shaper AG, Phillips AN, Pocock SJ, et al. Risk factors for stroke in middle aged British men. BM 1991:302:1111-16.

28 Bhopal R. Is research into ethnicity and health racist, unsound, or important science? BM 1997;314:1751-1.

29 Cruickshank FB, Beevers D, Osbourne V, et al. Heart attack, stroke, diabetes and hypertension in West Indians, Asians, and whites in Birmingham, England. BM 1980;281:1108.

30 Baker EH, Dong YB, Sagnella GA, et al. Association of hypertension with T594M mutation in $\beta$ subunit of epithelial sodium channels in black people resident in London. Lancet 1998;351:1388-92. 